
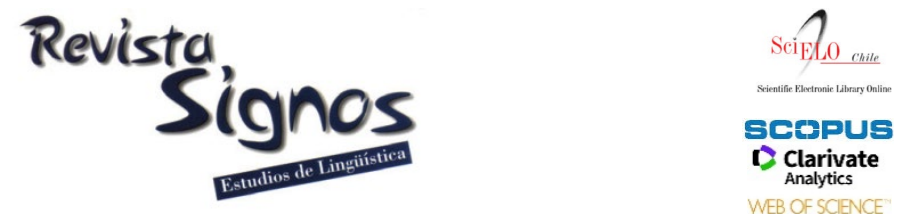

\title{
Is investigating discipline-specific academic lecture introductions a goal worth pursuing? A corpus-based study of the rhetorical organization of mathematics lecture introductions
}

\author{
¿Es la investigación de las introducciones a las ponencias \\ universitarias un objetivo digno de estudio? Un estudio basado \\ en corpus sobre la organización retórica de introducciones a las \\ ponencias de matemáticas
}

\author{
Branka Živković \\ UNIVERSITY OF MONTENEGRO \\ MONTENEGRO \\ brankaz@ucg.ac.me
}

\author{
Milica Vuković-Stamatović \\ UNIVERSITY OF MONTENEGRO \\ MONTENEGRO \\ vmilica@ucg.ac.me
}

Recibido: 05-XI-2019 / Aceptado: 03-VI-2020
DOI: $10.4067 /$ S0718-09342021000100120

\begin{abstract}
This study investigates the functional organization and linguistic signals of academic lecture introductions in the discipline of mathematics. The goal of the present study is two-fold: 1) to determine the rhetorical model of lecture introductions in the field of mathematics so as to help non-native students of English to overcome difficulties in understanding lectures in this discipline, and 2) to compare our discipline-specific model to the general models determined in the literature. Applying a genre-based approach, we explore the largest corpus used in this type of research to date - a corpus of 100 mathematics lecture introductions delivered at the MIT University (the USA). As the previous models, our model has two obligatory functions - 'setting up the lecture framework and putting the topic into context', which confirms the value of the previous research and suggests that discipline does not affect the rhetorical organization at the level of functions. However, another result found in this study is that the function 'putting topic in context' was realized more elaborately in mathematics lecture introductions than it was in the earlier studies, leading to a conclusion that disciplinespecificity can play a role at the level of subfunctions.
\end{abstract}


Key Words: Academic lecture introductions, mathematics lecture introductions, rhetorical organization, functions, subfunctions.

\section{Resumen}

Este estudio investiga la estructura funcional y señales lingüísticas de introducciones a las ponencias universitarias en la disciplina de matemáticas. Este estudio persigue un doble objetivo: 1) determinar el modelo retórico de introducciones a las ponencias en el campo de matemáticas con el fin de facilitar a los estudiantes no nativos de inglés sobrepasar dificultades de compresión de las ponencias en esta disciplina, y 2) comparar nuestro modelo de disciplinas específicas con los modelos generales determinados en la literatura. Al aplicar un enfoque basado en el género, exploramos el mayor corpus en este tipo de investigación hasta la fecha - un corpus de 100 introducciones a las ponencias de matemáticas impartidas en la Universidad MIT (MIT University, EE.UU.). La similitud entre nuestro modelo y los anteriores radica en la presencia de dos funciones obligatorias 'establecer el marco de la ponencia y poner un tema en contexto', lo que confirma el valor de las investigaciones anteriores y sugiere que la disciplina no afecta la organización retórica en el nivel de funciones. Sin embargo, otro resultado referente a una función más elaborada de 'poner un tema en contexto' en introducciones a las ponencias de matemáticas permite concluir que la especificación de disciplina puede desempeñar un papel en el nivel de subfunciones.

Palabras Clave: Introducciones a las ponencias universitarias, introducciones a las ponencias de matemáticas, organización retórica, funciones, subfunciones.

\section{INTRODUCTION}

Lectures are normally delivered as sizeable monologue stretches, which is why they may be difficult to follow by non-native speakers. Their introductions announce the topic of the lecture and at the same time they typically provide additional information as to its scope, structure, aims, general context and bonds with the previous knowledge. Lecture introductions can thus greatly facilitate the listening comprehension and following of the lecture content, which points to their pedagogical significance for the listeners, i.e. the students in case of academic lectures.

The analysis of the rhetorical organization of lecture introductions can provide models of their structure that students non-native to English can be familiarized with, resulting in their creation of "mental maps" which can assist the listeners in processing the lecture content (Lee, 2009: 43). Four genre analyses of lecture introductions have been produced to date - Thompson (1994), Lee (2009), Shamsudin and Ebrahimi (2012) and Yaakob (2013). The former three used relatively small corpora, consisting of 18, 10 and 6 lectures respectively, and the only study employing a more sizeable corpus was that of Yaakob (2013), who analyzed 89 lecture introductions from the BASE corpus ${ }^{1}$. Just one of these studies - that of Shamsudin and Ebrahimi (2012), used a discipline-specific corpus (engineering), but, as noted above, consisting of just 6 lectures. 
Bearing all this in mind, the primary aim of this paper is to produce a disciplinespecific rhetorical model of lecture introductions in the field of mathematics, so as to assist the students of this discipline who are non-native to English in their effort to listen to lectures delivered in this language. The model will be based on the largest corpus used to this purpose to date - a corpus of 100 mathematics lecture introductions delivered at the MIT University (the USA). Another goal of the study is to compare this discipline-specific model against the general ones already established in the literature. Should notable differences be found, such a finding will advocate for establishing lecture introduction models which are discipline-specific; however, should the differences prove negligible, this will confirm the broader value of the existing models.

\section{Theoretical background}

Genre analysis deals with the question of how language is used in institutional and professional settings. The followers of this approach are interested in both functional and linguistic descriptions of different genres. A genre is defined as "a distinctive category of discourse of any type, spoken or written" (Swales, 1990: 33), having its communicative purpose understood by the members of the genre community (Bhatia, 1993). There are three main theoretical trends and schools of genre studies: the Swalesean approach (1981, 1990), the New Rhetoric studies (Hyon, 1996) and the systemic-functional approach (Halliday, 1978; Halliday \& Hasan, 1989). We will focus on the Swalesean genre analysis, as this research article draws on it.

The study of genres from a rhetorical move perspective has its roots in Swales' work (1981, 1990), and "aims to determine the communicative purposes of a text by categorizing diverse text units according to the particular communicative purpose of each unit" (Parodi, 2010: 198). Swales (1981, 1990) studied the rhetorical organization of research article introductions and introduced his Creating a Research Space model (the CARS model), composed of the segments known as moves and steps. A move denotes a text component referring "to a defined and bounded communicative act that is designed to contribute to one main communicative objective, that of the whole text" (Lorés-Sanz, 2004: 282). Moves are further divided into steps as lower structural segments, each performing a specific communicative purpose linked to that of moves and the overall aim of the genre. Moves and steps form a unique rhetorical organization of a genre contributing to its identification and differentiation from other genres.

The Swalesean model "has had a tremendous influence on genre analysis in ESP" (Dudley-Evans, 2000: 6). His move-based approach was followed in the studies of many written academic genres. Some of them are: discussion sections of research articles (Hopkins \& Dudley-Evans, 1988) and dissertations (Dudley-Evans, 1986), abstracts (Huckin \& Olsen, 1983; Graetz, 1985; Salager-Meyer, 1992; Bhatia, 1993; 
Santos, 1996; Posteguillo, 1996; Martín-Martín, 2003) and textbooks (Tadros, 1989; Parodi, 2010). Unlike written academic texts, the Swalesean approach has been applied less frequently in research on spoken academic genres. It was employed in the analyses of biomedical research presentations (Dubois, 1980), plenary lecture and poster session discussions (Shalom, 1993), and lecture introductions (Thompson, 1994; Lee, 2009; Shamsudin \& Ebrahimi, 2012; Yaakob, 2013). These studies show that rhetorical move analysis can be used successfully as a framework for analyzing spoken academic genres as well.

This genre-based approach of segmenting a text into particular structural components and identifying their communicative functions has an educational objective - to clarify both to teachers and students how a spoken and written text type (a genre) varies according to its purpose, theme, audience and communication medium (Hyland, 1992). Understanding the structural and linguistic features of certain genres can be of help to both international and L1 students in developing their academic writing skills, or to professional writers wishing to publish in international journals (Dudley-Evans, 2000). In a similar vein, getting familiar with the rhetorical structure and linguistic markers of spoken academic genres can assist listeners in the development of their listening and speaking skills, and enhance the understanding and processing of the genre content (Shalom, 1993, Thompson, 1994).

\subsection{Academic lecture introductions}

From a genre analysis viewpoint, an academic lecture is defined as a "a class of communicative events, the members of which share some set of communicative purposes" (Swales, 1990: 58). It is the main genre in tertiary education:

"for a lecturer to impart knowledge to students about a particular subject and for students to obtain knowledge about a subject by listening to the lecturer" (Yaakob, 2013: 46).

Although its main purpose is the communication of the subject matter, it is also a value-laden genre as professors evaluate and critically examine the information presented (Thompson, 1994; Young, 1990, 1994). Students thus face the difficulty of processing information which are simultaneously transmitted and evaluated in lengthy lecture monologues. This is particularly true for students who are non-native English speakers, who frequently face difficulties in understanding lectures (Thompson, 1994).

Given that a structured sequence of utterances can help listeners to process the information in lectures (Thompson, 1994), it is very important for them to become familiar with the organization and purpose of lecture introductions. A lecture introduction is a subgenre of the lecture genre, as it is comparatively shorter and cannot stand on its own. It constitutes the beginning part of a lecture, which is very significant as its communicative purpose: 
"for a lecturer is to introduce the main lecture and other course issues and for the students to obtain information regarding the main lecture and course issues" (Yaakob, 2013: 46).

The information that students are given in lecture introductions concerns the lecture topic and its structure, scope, aims and general context. By providing students with both a structural and contextual framework for the remainder of the lecture, lecturers can "aid listeners in processing the information” (Lee, 2009: 44).

As already mentioned in the previous section, there is not much research on the functional organization of lecture introductions. To our best knowledge, four authors have analyzed this subgenre to date: Thompson (1994), Lee (2009), Shamsudin and Ebrahimi (2012), and Yaakob (2013).

Thompson (1994) examined the rhetorical structure of a mixed corpus of 18 lecture introductions in applied linguistics, engineering and medicine. She used the terms 'functions' and 'subfunctions' for Swalesian 'moves' and 'steps'. Not aiming to differentiate between the rhetorical models in the mentioned disciplines, Thompson introduced a model composed of two main functions -SETTING UP THE LECTURE FRAMEWORK and PUTTING TOPIC IN CONTEXT. The first function is metalinguistic, giving the audience information on the lecture discourse. Hence, it is realized through four subfunctions: 'announce the topic', 'indicate scope', 'outline the structure' and 'present aims'. The second function, PUTTING TOPIC IN CONTEXT, provides the audience with the information on the lecture content through the following subfunctions: 'show importance/relevance of topic, relate 'new' to 'given' and refer to earlier lectures'.

Following Thompson (1994) in his analysis of the impact of class size on the rhetorical organization of 10 lecture introductions from various disciplines taken from MICASE, Lee (2009: 46) identified another move - WARMING UP, in which lecturers:

"warm up the audience prior to the actual lecture, offering them general course information and course-related asides (or digressions), looking ahead to future lectures, and/or telling an anecdote".

Lee (2009) concluded that in larger classes lecturers frequently reminded students of class-related issues and upcoming lectures, whereas in small classes they made more digressions. However, Lee (2009) pointed out that his study was limited by its rather small data set.

Shamsudin and Ebrahimi's (2012) investigation of the corpus of six lecture introductions in the field of engineering is based on Thompson's (1994) and Lee's (2009) models. They observed that the rhetorical model of engineering lecture 
introductions was similar to Lee's (2009), with some differences at the level of the specific steps.

Compared to previous studies, Yaakob (2013) used a larger corpus, including 89 lecture introductions taken from the BASE, and introduced two main orientations: CONTENT ORIENTATION and LISTENER ORIENTATION, taken from the study of Dubois (1980). The content orientation realizes Thompson's two functions (1994) - SETTING UP THE LECTURE FRAMEWORK and PUTTING TOPIC IN CONTEXT, whereas the listener orientation, realised through seven subfunctions: 'greeting', 'announcement', 'check comprehension', 'check comprehension feedback', 'refer to handout' and 'refer to visual', was identified and added by Yaakob (2013). As stated earlier, Yaakob (2013) explored a mixed corpus of arts and humanities, social, physical and life science.

Another study of particular relevance for the study at hand is that of Alsop and Nesi (2015). As opposed to the authors listed above, Alsop and Nesi find that the value of studying lecture introductions was rather overstated in the previous literature. They also point to the difficulties of separating lecture introductions from the rest of the lectures. While acknowledging the fact that the said technical difficulties do arise in some cases, we would agree with Thompson (1994), Lee (2009), Shamsudin and Ebrahimi (2012), and Yaakob (2013), in their assessment of that investigating lecture introductions is, in fact, a goal well worth pursuing. We will present our arguments in more details in the discussion section of the paper.

The next section introduces the data, method and procedure applied in the analysis of mathematics lecture introductions, followed by the results, discussion and conclusion sections.

\section{Data and method}

The corpus compiled for this study consists of 100 mathematics lecture introductions delivered at the MIT University in the last two decades, containing a total of 13,054 words, with the average lecture introduction's duration of 1 minute 8 seconds (or 130.54 words). The lectures they were extracted from were video recorded, and their videos and transcripts are available at the MIT OpenCourseWare website (https://ocw.mit.edu/courses/audio-video-courses/). In the category marked Mathematics, we randomly chose 100 undergraduate lectures.

We opted for MIT OpenCourseWare as the source for our corpus for two reasons. Firstly, this number of discipline-specific lectures could not be found in the standard corpora such as the MICASE (Michigan Corpus of Academic Spoken English) or the BASE (the British Academic Spoken English Corpus). Among other speech events, the MICASE includes 62 lectures in four broad academic divisions - Humanities and 
Arts, Social Sciences and Education, Biological and Health Sciences, and Physical Sciences and Engineering (Simpson, Lee \& Leicher 2002); among these, there is only one lecture from the field of mathematics. On the other hand, the BASE contains 160 lectures coming from four broad fields (Arts and Humanities, Life and Medical Sciences, Physical Sciences, Social Studies and Sciences) - however, it has only four mathematics lectures. What also recommended MIT OpenCourseWare for the present study is the fact that, apart from the transcripts, it also contains the video recordings of the lectures, which can be very useful for the analysis.

The genre analysis was employed in analyzing the rhetorical organization of mathematics lecture introductions. Out of four genre analyses of lecture introductions to date, two studies, those of Lee (2009) and Shamsudin and Ebrahimi (2012), adopted the Swalesean terms 'moves' and 'steps'. The other two analyses, those of Thompson (1994) and Yaakob (2013), referred to 'moves' and 'steps' as 'functions' and 'subfunctions' respectively. Thompson (1994) employed the term function to refer to the rhetorical functions and 'subfunction' to indicate the realisation of the rhetorical function of lecture introductions. Yaakob (2013) explained his choice more explicitly. Besides stating that these terms were easier for the analyst and the coder to process, Yaakob (2013') argued that they also reflected the nature of the lecture spoken genre, which presupposes that less thought and editing are put into it than it is the case with the research article as a written genre. In the vein of Thompson (1994) and Yaakob (2013), we will also employ the terms 'functions'and 'subfunctions' to describe the rhetorical organization of mathematics lecture introductions.

As for the procedure for separating lecture introductions from the body of the lectures, the following were used:

1. boundary markers,

2. markers initiating the body of the lecture, including the discourse markers with the initiating function and the constructions semantically indicating the beginning of the central part of the lecture,

3. visual cues (as in Yaakob, 2013).

The full lists of such devices found in our corpus is given below (Table 1). 
Table 1. The cues used to separate lecture introductions from the body of the lecture.

\begin{tabular}{|c|c|}
\hline $\begin{array}{l}\text { Boundary markers and markers initiating the } \\
\text { central part of the lecture ( } 91 \text { lectures) }\end{array}$ & Visual cues (66 lectures) \\
\hline $\begin{array}{l}\text { So } \\
\text { Ok/Okay } \\
\text { Well } \\
\text { Now } \\
\text { Alright/All right } \\
\text { Right } \\
\text { And } \\
\text { Filled pause } \\
\text { Anyway } \\
\text { First, } \\
\text { The first thing I'd like to do... } \\
\text { The first (followed by a pause) } \\
\text { First of all, } \\
\text { Let me remind you... } \\
\text { Let me first remind you... } \\
\text { Let me first tell you... } \\
\text { Let me just start by... } \\
\text { Let's get started } \\
\text { Let's begin with... } \\
\text { Let's begin by... } \\
\text { Let's see } \\
\text { I'd like to start with... } \\
\text { Here we go } \\
\text { I'm going to start by... }\end{array}$ & $\begin{array}{l}\text { Looking at the notes } \\
\text { Taking the notes from the desk } \\
\text { Going to the blackboard } \\
\text { Moving away from the blackboard } \\
\text { Turning to the blackboard } \\
\text { Start writing on the blackboard } \\
\text { Start writing on the second blackboard } \\
\text { Turning on the first ppt slide } \\
\text { Showing the first ppt slide } \\
\text { Switching the ppt slides } \\
\text { Looking at the ppt presentation } \\
\text { Taking a chalk } \\
\text { Writing the title of the unit on the blackboard } \\
\text { Pointing to the title written on the blackboard } \\
\text { Start writing under the title on the blackboard } \\
\text { Taking a deep breath } \\
\text { Turning to the audience } \\
\text { Clasping hands }\end{array}$ \\
\hline
\end{tabular}

The boundary markers and the markers/constructions with the initiating function were present in $91 \%$ of the lectures and thus proved most useful for the segmentation task. It should be noted that most frequently they appeared in combinations (e.g. OK. So,...; So let's get started...), and that in 51 lectures they were preceded by a lengthy pause and in another 11 lectures by a filled pause (uhm, hm..). The lecture-initial markers were discounted, and as for determining which marker to use to mark the separation point (as sometimes several such markers appeared in the very lecture introduction), we applied two criteria: 1 . the existence of visual cues, which was useful in about $2 / 3$ of the cases, 2. semantic criteria - the lecture introduction was considered to have ended after the topic announcement and/or contextualization, i.e. before the lecturer's going into the content of the topic lectured on (typically, providing a definition of a key term, asking students whether they knew what it was, and similar). Below is one of the lecture introductions (L42), which we will use for an illustration of this procedure:

- So let's begin. Today, I'm going to review of linear algebra. So I'm assuming that you already took some linear algebra course. And I'm going to just review the relevant content that will appear again and again throughout the course. But do interrupt me if some concepts are not clear, if you don't remember some concept from linear algebra. I hope you do. But please let me know. I just don't know. You have very different background knowledge. So it's hard to tune 
to one special group. So I tailored these lecture notes so that it's a review for those who took the most basic linear algebra course. So if you already have that experience, and don't understand it, please feel free to interrupt me./

[Visual cue: turns to the blackboard and is about to write on it, while still talking] So I'm going to start by talking about matrices. A matrix, in a very simple form, is just a collection of numbers...

The fifth use of the discourse marker so was used the separation point in L42 presented above. While the lecture-initial so and the initiating construction let's begin were discounted just by being found at the very beginning of the lecture, what made us decide that the fifth use of this marker was the right place to make the cut are the visual cues we collected by watching the video ('the lecturer turns to the blackboard and appears to be about to write on it'), as well as its being followed by another initiating construction, metadiscoursal in this case ('I'm going to start by talking about...). Also, after the announcement of the topic, the lecturer is still not going into the content of the lecture and instead makes comments on how the notes were tailored to the students' knowledge, inviting them to interrupt him if they cannot follow - making a sort of a metadiscoursal arrangement with them about what is to follow. The fifth discourse marker so and the said initiating construction are also followed by a definition of the term which is the focus of the topic at hand (matrices). In most lectures, it is a combination of such visual and linguistic cues that proved most indicative as to where to make the cut. It must granted, though, that some other lecture introductions proved much harder to segment; however, these were presented in fewer than $10 \%$ of our lectures and were resolved through discussion of the two authors.

After this, the analysis we undertook roughly corresponds to Upton and Cohen's (2009) move analysis model, which is a refinement and adaptation of the top-down model for using corpus analysis to describe discourse structure proposed by Biber, Connor and Upton (2007). We first determined the purpose of the genre of lecture introductions, after which we identified the possible functions, as well as the functional and/or semantic themes in proximity of each other, reflecting possible subfunctions. At this point, the two researchers together analyzed the structure of the first 20 lecture introductions, so as to establish the analysis criteria, i.e. the coding protocol. Following this, the remaining 80 lecture introductions were analyzed independently by the two researchers, after which the results were compared. The interrater agreement of over 90\% was achieved, and the points of disagreement were resolved in discussion. Next, the researchers classified the functions and the subfunctions into a model and calculated their frequencies, after which a linguistical analysis of the functions and the subfunctions ensued. The final step in the analysis involved describing the entire corpus of the mathematics lecture introductions in terms of its typical rhetorical structure. 
This methodology resulted in a rhetorical model of mathematics lecture introductions, which is presented in the next section of the paper.

\section{Results}

The analysis of our corpus of mathematics lectures yielded the following rhetorical organization (Table 2):

Table 2. Functions and subfunctions in maths lecture introductions.

\begin{tabular}{|l|l|}
\hline \multicolumn{1}{|c|}{ FUNCTIONS AND SUBFUNCTIONS } & Frequency \\
\hline FUNCTION: ORIENTING THE STUDENTS & 36 \\
\hline Subfunction: Greeting the students & 26 \\
\hline Subfunction: Introducing the teacher(s) & 7 \\
\hline Subfunction: Thanking the students & 5 \\
\hline FUNCTION: MAKING TECHNICAL REMARKS & 13 \\
\hline \multicolumn{1}{|c|}{ Subfunction: Referring to audio and video } & 5 \\
\hline Subfunction: Giving information about the & 8 \\
\hline FUNCTION: SETTING UP LECTURE FRAMEWORK & 100 \\
\hline Subfunction: Announcing the topic & 98 \\
\hline Subfunction: Indicating the scope & 22 \\
\hline Subfunction: Outlining the structure & 34 \\
\hline Subfunction: Presenting aims & 6 \\
\hline FUNCTION: PUTTING TOPIC IN CONTEXT & 74 \\
\hline Subfunction: Showing the importance/relevance of topic & 19 \\
\hline Subfunction: Referring to previous lectures & 49 \\
\hline Subfunction: Referring to the course & 17 \\
\hline Subfunction: Referring to future lectures & 16 \\
\hline Subfunction: Referring to other courses & 6 \\
\hline Subfunction: Referring to general knowledge & 2 \\
\hline Subfunction: Relating new to given & 20 \\
\hline
\end{tabular}

What the previous models (Thompson, 1994; Lee, 2009; Yaakob, 2013) agreed on was the presence of two main functions in the rhetorical organization of lecture introductions - that of SETTING UP THE LECTURE FRAMEWORK and of PUTTING THE TOPIC INTO CONTEXT, which our model also confirmed. These were present in an overwhelming majority of the lectures $(100 \%$ and $74 \%$, respectively), which is why we may say that they are obligatory functions.

In addition to the mentioned functions, Lee (2009) and Yaakob (2013) included another move or function, as suggested in the introductory section of this paper, which they called WARMING UP and LISTENER ORIENTATION, respectively. Our model also includes additional functions to the two main ones suggested above, but, unlike Lee (2009) and Yaakob (2013), we decided to present them as two separate functions. Namely, the subfunctions in question serve different communicative purposes which could not be simply subsumed under one heading. For instance, 'referring to audio and video' is not a matter of warming up for the lecture, nor is 
'giving information about the course', such as information on the upcoming tests, which we framed as the function MAKING TECHNICAL REMARKS. This function might also be used later during the lecture, but is probably most often at the beginning ( $13 \%$ of our lecture introductions featured it). This function is preceded by the subfunctions such as 'greeting the students, thanking the students and introducing the teacher or teachers' (in case there are guest lecturers), which we grouped within the function ORIENTING THE STUDENTS. We felt that 'warming up' is not a term which can cover all the subfunctions encompassed in our two functions, and that ORIENTING THE STUDENTS, modelled on the term used by Yaakob (following Dubois, 1980) would encapsulate its essence closer.

The function ORIENTING THE STUDENTS was present in just over a third of the lectures $(36 \%)$. Its most common subfunction is 'greeting the students'. This speech act is commonly realized through a restricted number of fixed phrases, such as:

1) Good morning, everyone... (L1)

2) Welcome back to $6046 \ldots$ (L2)

The speech act of greeting is present in just over a quarter of the lectures. The other two subfunctions, which correspond to the speech acts of introducing and thanking, are much less present. 'Introducing the teacher(s)' is common in the first lecture of the semester, in case there is a substitute teacher or if there are guest teachers:

3) All right, let's get started. I am Erik Demaine. You can call me Erik... (L12)

4) I am Haynes Miller, I am substituting for David Jerison today... (L89)

5) Anyway, welcome today. Stefan Andreev is our guest speaker from Morgan Stanley, And I understand you have a degree, a PhD degree in chemical physics. (L96)

This subfunction tends to be more elaborate if the host teacher is introducing a guest speaker, as can be seen in example 5. On the other hand, 'thanking the students' tends to be a very simple subfunction, normally featuring the performative verb 'to thank':

6) Thanks for coming to the lecture. (L15)

7) Thanks for coming on quiz day. (L18)

Thanking the student for attendance is not very common - it was present in only $5 \%$ of the lectures.

The function MAKING TECHNICAL REMARKS was found to be optional, as evidenced by its relatively low presence (it occurred in just $13 \%$ of the lectures). It consists of two subfunctions, the first one of which refers to 'referring to the sound and video', as illustrated by the following: 
8) Hello. One, two, three. Can you hear me? (L100)

9) OK, when the camera says, we'll start. You want to give me a signal? OK. (L75)

What we have in example 8 is typical of a large-class lecture, in which microphones are used. On the other hand, referring to video recording is a peculiarity of our corpus. Asking questions is typical of this subfunction, as well as the interaction of the teacher and the students or technical personnel. This subfunction is not very frequent, i.e. it appeared in just $5 \%$ of the lectures.

'Giving information about the course' is a subfunction which we found in $8 \%$ of the lectures. It typically refers to quiz or exam information, survey, or the schedule and location of the classes. In the models provided by Lee (2009), and Shamsudin and Ebrahimi (2012), there is a step referred to as housekeeping, which would encompass just the schedule and the location information. In our corpus, this subfunction mostly refers to the exam information, which is why we opted for another term. Let us have a look at the following:

10) Remind you there's a quiz coming up soon, you should be studying for it. (L66)

11) And so, if you haven't reviewed in appendix B recently, please sit down and review appendix B. It will pay off especially during our take-home quiz. (L69)

The purpose of this subfunction, as realized in the examples above, is not just to provide quiz information to the students, but also to encourage them to study more intensively. As such, this subfunction can, in a way, be related to the subfunction 'showing the importance/relevance of topic' from the function PUTTING TOPIC IN CONTEXT. It frequently contains expressing strong advice ('you should be studying' (10); 'please sit down and review' (11)).

The function SETTING UP LECTURE FRAMEWORK is present in all of the lectures, most commonly through its step 'announcing the topic' ( $98 \%$ of the lectures). As suggested by Thompson (1994), this function is metalinguistic in its essence, bearing in mind that it gives information on the lecture itself - what the topic will be, to which extent it will be covered, what the structure will be, and what the aim of presenting the topic is. The structure of this function is the same in all the previous studies, including this study, which suggests a uniformity of this move across disciplines.

As noted above, 'announcing the topic' is the most frequent subfunction. Basically, the instructor is presenting the topic, as in the following:

12) ... Today we start an exciting series of algorithms for graphs... (L17)

13) ... Today we're going to do another divide and conquer algorithm called the fast Fourier transform. It is probably the most taught algorithm at MIT. (L12) 
14) $\mathrm{OK}$, this lecture is about the slopes, the derivatives, of two of the great functions of mathematics: sine $\mathrm{x}$ and cosine $\mathrm{y}$. (L55)

15) OK, I thought I would talk today about power series. (L58)

Typically, proximal deictic words are present in the subfunction (such as 'today' and 'this', as well as the first-person pronouns ('we' and I), in the examples above). Some contain metalinguistic verbs such as 'talk' (example 15), although many do not, as mathematics lectures do not involve just talking, but also 'doing 'something, such writing out a series of equations on the blackboard (in example 13, the verb 'to do' is used instead).

Scope was indicated in just over a fifth of the lectures. Let us have a look at some of the examples:

16) ... I'll start a quick preview... (L14)

17) OK. Hi. I thought I'd give you a short lecture about how logarithms are actually used. (L60)

18) So, today we'll actually just do a brief chapter on Baysian statistics... (L97)

As can be seen from the examples, it is frequently expressed via adjectives, particularly adjectives which denote brevity, which act as hedges. They are used to encourage the students to 'buy' their attention with the promise of not covering too much or going too deep into the subject matter, thus avoiding complexity.

'Outlining the structure' was present in just over a third of the lectures (34\%). Let us have a look at the following:

19) So we will start from bonds, which is probably the most simple interest rate product on the market. Then we will discuss swaps. We will build a yield curve. And we will see how yield curve models can be improved to satisfy needs of actual trader. And at the end, we'll look at the very nice example of ill-posed problem of calibrating the two-dimensional volatility surface necessary for volatility model... (L100)

20) So, today at Wednesday we're going to talk about parallel algorithms...The second topic we're going to cover is going to be caching, and how you design algorithms for systems with cache. (L65)

21) And very quickly, we'll talk about what it means to actually exchange a secret. So we'll talk about key exchange. And then I'll move to asymmetric key encryption... (L5)

In this subfunction, grammatical cohesion is commonly achieved via temporal expressions ('then', 'at the end' (19 and 21)), verbs suggesting movement ('start' (19), 'move' (21)), metalinguistic verbs ('discuss' (19), 'talk' (20, 21)), as well as ordinal numbers ('second' (20)). Indicating scope was frequently intertwined with this 
subfunction, as in example 21 ('very quickly'). The teachers commonly used the future verb forms for this subfunction.

'Presenting aims was' found only in $6 \%$ of the lectures, which makes it more of a rarity:

22) $\mathrm{OK}$, hi. This is the second in my videos about the main ideas, the big picture of calculus. And this is an important one, because I want to introduce and compute some derivatives. (L51)

23) $\mathrm{OK}$, this is the second lecture on determinants... And my goal today is to find a formula for the determinant. (L77)

In our corpus, this subfunction was typically indicated by the nouns 'aim' or 'goal' (as used in 23), or the verb phrase 'I want to' (22).

The function PUTTING TOPIC IN CONTEXT is another obligatory function, found in almost three quarters of the lectures (74\%). It was also obligatory in other studies, as suggested earlier. However, in our study, we identified more subfunctions than it was the case in the previous ones, perhaps due to the fact that we used a larger corpus. Admittedly, some of these were not that frequent.

We will start with the first subfunction found within this function: 'showing importance/relevance of topic', featured in slightly less than a fifth of the lectures $(19 \%)$ :

24) Today we continue our theme of data structures but this time, instead of doing a fancy cool data structure, we're going to look at fancy cool analysis techniques for data structures. And these are useful for tons of different data structures, especially in the context when you're using a data structure to implement an algorithm. (L2)

25) The general topic for today is going to be oscillations, which are extremely important in the applications and in everyday life. (L43)

26) So that's what we did last time, and today I want to finish up with other points of view on what a derivative is. So this is extremely important, it's almost the most important thing I'll be saying in the class. (L87)

In the examples above, importance of the topic is indicated by using the adjectives 'useful' (24) and 'important' $(25,26)$, commonly coupled with intensification ('useful for tons of things' (24), 'extremely important' $(25,26))$. Some lecturers also indicate how attractive or interesting the topic of the lecture is, as in 24 ('fancy cool)' - this is an element of 'evaluation,' which can be employed throughout the lecture introduction. This subfunction frequently follows the announcement of the topic. 
The following subfunctions include referring to other lectures (earlier and future), the course itself or other courses. The most frequent of them is 'referring to earlier lectures', present in almost half the lectures (49\%):

27) ...So two lectures ago we saw how to prove a problem is NP-hard. Last lecture we saw if you want polynomial time but you're willing to put up with a not perfect solution, but you want to get within some factor of the best solution, that's approximation algorithms. Today we're going to do a different thing called fixed parameter algorithms. (L3)

28) $\mathrm{OK}$, earlier lecture introduced the logarithm as the inverse function to the exponential. And now it's time to do calculus, find its derivative. (L46)

Referring to previous lectures is typically related to the today's topic, and it provides the context for it. Distal deictic words, typically temporal ('ago', 'last' (27), 'earlier' (28)), are commonly followed by the proximal ones ('today '(27) and 'now '(28)). This subfunction tends to be longer than the other ones.

Subfunction 'referring to the course 'was found in 17 lectures. No previous study identified this subfunction and this is one of the contributions of the present study. Let us have a look at the following:

29) Okay. This is lecture six in linear algebra... (L74)

30) All right, welcome to the final lecture of 6046. (L7)

31) This is lecture twelve. OK. We've reached twelve lectures. (L72)

In this subfunction, lecturers typically point out where the current lecture takes place within the overall framework of the course. The fact that the lectures from our corpus were recorded, depriving them of the physical context and a sense of the time elapse of the course when they are watched as videos, might have contributed to the fact that we found this subfunction in almost a fifth of the lectures. However, it seems that mathematics lecturers are rather fond of providing a detailed context for the lectures, bearing in mind that they also like to refer to future lectures and other courses relatively often.

In 16 lectures, lecturers referred to future lectures. This subfunction was earlier identified by Yaakob (2013), as well as by Alsop and Nesi (2013, 2014, 2015), and our study also confirms the existence of this optional subfunction:

32) So, again welcome to 18.01. We're getting started today with what we're calling Unit One, a highly imaginative title. And it's differentiation. So, let me first tell you, briefly, what's in store in the next couple of weeks... (L86)

33) Let's get started. Welcome back to 6046. Today, we start an exciting series of algorithms for graphs. We've done a lot of data structures. We're starting to get back into algorithms with dynamic programming last week. And today and the next few lectures, we're going to see lots of cool algorithms about graphs. (L17) 
In examples 32 and 33, the lecturers referred to the courses lectured, indicating their exact labels. Referring to previous lectures (in 33) is typically continued by the topic for today, after which referring to future lectures normally takes place $(32,33)$. Temporal expressions such as 'next' and 'later' are typical. We also note that positive evaluation is frequently intertwined within these subfunctions ('highly imaginative' (32), 'exciting, cool' (33)).

'Referring to other courses' was present in 6 lectures. This subfunction has not been identified previously in the literature. Let us consider the following:

34) So we're going to be doing dynamic programming, a notion you've learned in 6006. We'll look at three different examples today. The first one is really at the level of 006, a cute little problem on finding the longest palindromic sequence inside of a longer sequence. (L19)

In 34, the lecturer refers to two other courses, using their number codes (6006 and 006). The fact that mathematics content highly depends and builds on the previous knowledge, whereby the knowledge from some of its disciplines is frequently a prerequisite for the other disciplines, might contribute to the mathematics lecturers' being prone to provide a detailed context for the topic and content of their current lecture.

In two lectures, the general knowledge of the students was referred to instead. This subfunction has not been identified in the literature previously. More data, i.e. a larger corpus, however, is needed to assess its status with more certainty.

'Relating new to given' is present in all the models from the literature, as well as in our model. In our corpus it featured a frequency of $20 \%$ and was used together with the subfunctions 'referring to earlier lectures', 'referring to other courses and referring to general knowledge', to show how the new content related to the previous in terms of their similarities or differences. Let us have a look at the following examples:

35) ...So more of the same in terms of cryptography and cryptographic techniques similar to Tuesday's lecture. So if you liked it, you'll like this one. If you didn't like it, well, it's going to be more of the same, so sorry. (L5)

36) OK so today, you're going to see something new. In fact all this week, you're going to see something that's quite different from what you've been studying in this course. These are algorithms. But they're for a completely different sort of model. (L16)

37) And you'll probably see problems here, at least alternating coin game, that are beyond 006 in the sense that it wasn't covered. (L19)

The comparison-contrast rhetorical model present here is commonly marked by the signal words and phrases such as 'the same', 'similar' (35) and 'different' (36), but 
other ways of comparing the already given content to the new one are employed as well. For instance, in 36, 'new' is used to compare the present to the given, whereas in 37 , it is said that the present content is 'beyond' what was covered in another course.

\section{Discussion}

Our analysis showed that the two obligatory functions were SETTING UP LECTURE FRAMEWORK and PUTTING TOPIC INTO CONTEXT. The other two functions, ORIENTING THE STUDENTS and MAKING TECHNICAL REMARKS, featured much lower frequencies. In addition, the latter two are not as helpful in facilitating the students to follow the ensuing lecture content, and Thompson (1994) was perhaps right to include just SETTING UP LECTURE FRAMEWORK and PUTTING TOPIC INTO CONTEXT into her overview of the strategies used in lecture introductions.

As indicated in the introduction, Alsop and Nesi (2015) consider that the importance of lecture introductions for lecture comprehension is 'overemphasized', having found that some of the introductory elements are repeated later in the lecture and that the lecture introductions are sometimes difficult to separate from the rest of the lecture. We will discuss both these points below.

The functions that Alsop and Nesi (2015) investigated and found repetitive throughout the lecture include 'housekeeping' (which corresponds to our function MAKING TECHNICAL REMARKS) and 'summary', which subsumed both our obligatory functions. As indicated above, the two obligatory functions (SETTING UP LECTURE FRAMEWORK and PUTTING TOPIC INTO CONTEXT) are most relevant for comprehending the lecture and we will focus on these now. These two functions set up and contextualize the content of the 'overall' content of the lecture, and, as such, their significance is the greatest at the beginning of the lecture, as they create the general framework which facilitates the comprehension of the upcoming individual pieces of new information by positioning them in and relating them to the whole of the lecture. For instance, it is difficult to expect that 'announcing the topic', the most frequent subfunction in lecture introductions, could re-occur later in the lecture. Likewise, setting the lecture scope and structure in the introduction refers to the entire lecture and facilitates its following in the entirety, and the re-occurrence of these elements later in the lecture could refer to just the individual theme cycles and their significance at the later stages would be limited to just certain portions of the lecture. We conclude that Alsop and Nesi (2015) are right to say that these elements re-occur later in the lecture - however, we are of the opinion that their re-occurrence does not subtract from their value at the beginning of the lecture, and supplement this by suggesting that their value at the beginning of the lecture is, in fact, the greatest, in the sense that they facilitate the following of the entire lecture, and not just the individual or the remaining parts of the lectures. 
When it comes to separating the lecture introduction from the body of the lecture, in the literature it has been suggested that the separation points are marked by boundary markers, such as 'OK', 'alright', as well as intonation, etc. (Thompson, 1994), and that visual cues from the video recordings could be used to this purpose as well (Yaakob, 2013). In the methodology section, we provided a detailed overview of the cues we used, along with the exhaustive lists of them found in our corpus and an illustration of our segmenting procedure - compared to the previous studies, our study is the one offering the most detailed information on how the segmenting task was accomplished. Alsop and Nesi (2015) are again right to say that the lecture introductions may sometimes be difficult to set apart from the body of the lectures, however, the cases which were not clear-cut presented fewer than $10 \%$ of the cases in our study, and we also consider that this methodological uncertainty cannot subtract from the value of understanding what is said in the lecture introduction.

Therefore, as Thompson (1994), Lee (2009), Shamsudin and Ebrahimi (2012) and Yaakob (2013), we believe that lecture introductions are valuable for framing the entire lecture and that by familiarizing the students who are non-native to English with their structure and recommending them to particularly concentrate on this part of the lecture, will be beneficial for their overall lecture comprehension.

When it comes to the resemblance of our model to the ones previously established in the literature, we may say that the model is very similar to existing ones. Mathematics lecture introductions do not differ much from the lecture introductions from other disciplines and providing discipline-specific models of lecture introductions is not really necessary, as this study has shown. Our model differs in a somewhat different organization of the optional functions (which we presented as two rather than one) and in a more elaborate structure of the function PUTTING TOPIC IN CONTEXT. This more elaborate organization of the said function may indeed be discipline-specific as perhaps mathematics warrants more contextualization than some other disciplines, bearing in mind that the previous knowledge plays a vital part in following any mathematics lecture. Therefore, it seems that discipline-specificity plays a part at the level of the subfunctions involved in the model, but not at the level of the functions involved.

\section{CONCLUSION}

In this paper, we established a rhetorical model of the structure of mathematics lecture introductions based on a corpus of 100 lectures delivered at the MIT University. It resembles the models already established in the literature, but also displays some discipline-specific features in the organization of certain functions. We showed that two functions were obligatory - SETTING UP LECTURE FRAMEWORK and PUTTING TOPIC IN CONTEXT and argued that their value 
at the beginning of the lectures is significant in terms of their allowing the students to create a general mental framework for the lecture, which should facilitate the comprehension of the lecture content presented after the lecture introduction.

Our findings do not point to a need to establish further discipline-specific models as their overall rhetorical structure will likely correspond to that of the general models, with the differences potentially arising at the level of optional functions and in terms of the elaborateness of the subfunctions. Using the largest corpus for this type of a study to date, we proved the broader value of the existing models, which is why a recommendation for further studies does not go in the direction of additional structural analyses. Instead, we would recommend empirically investigating how familiarizing the students who are non-native to English with the rhetorical organization of lecture introductions affects their understanding and following of the lecture contents.

\section{REFERENCES}

Alsop, S. \& Nesi, H. (2013). The summarising function of university Engineering lectures: a cross-cultural perspective. In A. N. Archibald (Ed.) Multilingual theory and practice in applied linguistics: Proceedings of the 45th annual meeting of the British Association for Applied Linguistics (pp.11-14). London: Scitsiugnil Press.

Alsop, S. \& Nesi, H. (2014). The pragmatic annotation of a corpus of academic lectures. In N. Calzolari, K. Choukri, T. Declerck, H. Loftsson, B. Maegaard, J. Mariani, A. Moreno, J. Odijk \& S. Piperidis (Eds.) Proceedings of LREC 2014, Ninth international conference on language resources and evaluation (pp. 1560-1563). Reykjavik: ELRA.

Alsop, S. \& Nesi, H. (2015). Introductions in engineering lectures. In F. Formato \& A. Hardie (Eds.) Proceedings of the 8th International Corpus Linguistics conference (CL2015) (pp. 19-22). Lancaster: UCREL.

Bhatia, V. K. (1993). Analysing genre: Language use in professional settings. London and New York: Longman.

Biber, D., Connor, U. \& Upton, T. (2007). Discourse on the move: Using corpus analysis to describe discourse structure. Amsterdam: John Benjamins.

Dubois, B. L. (1980). Genre and structure of biomedical speeches. Forum Linguisticum, 5, 140-169.

Dudley-Evans, T. (1986). Genre analysis: An investigation of the introduction and discussion sections of MSc dissertation. In M. Coulthard (Ed.), Talking about text. Discourse analysis monograph 13 (pp. 128-145). Birmingham: University of Birmingham. 
Dudley-Evans, T. (2000). Genre analysis: A key to a theory of ESP? Iberica, 2, 3-11.

Graetz, N. (1985). Teaching EFL students to extract structural information from abstracts. In J. M. Ulijin \& A. K. Pugh (Eds.), Reading for professional purposes (pp. 123-135). Leuven: ACCO.

Halliday, M. A. K. (1978). Language as social semiotic: The social interpretation of language and meaning. London: Edward Arnold.

Halliday, M. A. K. \& Hasan, R. (1989). Language, context, and text: Aspects of language in a social-semiotic perspective. Oxford: Oxford University Press.

Hopkins, A. \& Dudley-Evans, T. (1988). A genre-based investigation of the discussion sections in articles and dissertations. English for Specific Purposes, 7, 113-121.

Huckin, T. \& Olsen, L. A. (1983). English for science and technology: A handbook for nonnative speakers. New York: McGraw-Hill.

Hyland, K. (1992). Genre analysis: Just another fad. Forum, 33(2), 14-17.

Hyon, S. (1996). Genre in three traditions: Implications for ESL. TESOL Quarterly, 30, 693-720.

Lee, J. J. (2009). Size matters: An exploratory comparison of small- and large-class university lecture introductions. English for Specific Purposes, 28, 42-57.

Lorés-Sanz, R. (2004). On RA abstracts: From rhetorical structure to thematic organization. English for Specific Purposes, 23(3), 280-302.

Martín-Martín, P. (2003). Personal attribution in English and Spanish scientific texts [on line]. Retrieved from: www.publicacions.ub.es/revistes/bells12/PDF/art09.pdf

Parodi, G. (2010). The rhetorical organization of the textbook genre across disciplines: A 'colony-in-loops'? Discourse Studies, 12(2), 195-222.

Posteguillo, S. (1996). A genre-based approach to the teaching of reading and writing abstracts in computer science. In J. Pique, J.-V. Andreu-Beso \& D. J. Viera (Eds.), English in specific settings (pp. 47-57). Valencia: NAU Llibres.

Salager-Meyer, F. (1992). A text-type and move analysis study of verb tense and modality distribution in medical English abstracts. English for Specific Purposes, 11(2), 93-113.

Santos, M. B. D. (1996). The textual organization of research of research paper abstracts in applied linguistics. Text \& Talk, 16(4), 481-500. 
Shalom, C. (1993). Established and evolving spoken research process genres: Plenary lecture and poster session discussions at academic conferences. English for Specific Purposes, 12, 37-50.

Shamsudin, S. \& Ebrahimi, S. J. (2012). Analysis of the moves of engineering lecture introductions. Procedia - Social and Behavioral Sciences, 70, 1303-1311.

Simpson, R. C., Lee, D. Y. W. \& Leicher, S. (2002). MICASE manual. Ann Arbor, MI: English Language Institute, The University of Michigan [on line]. Retrieved from: https://ca.talkbank.org/access/Odocs/MICASE.pdf

Swales, J. (1981). Aspects of article introductions. Birmingham: University of Aston.

Swales, J. (1990). Genre analysis: English in academic and research settings. Cambridge: Cambridge University Press.

Tadros, A. (1989). Predictive categories in university textbooks. English for Specific Purposes, 8(1), 17-32.

Thompson, S. (1994). Frameworks and contexts: A genre-based approach to analysing lecture introductions. English for Specific Purposes, 13(2), 171-186.

Upton, T. A. \& Cohen, M. A. (2009). An approach to corpus-based discourse analysis: The move analysis as example. Discourse studies, 11(5), 585-605.

Yaakob, S. (2013). A genre analysis and corpus based study of university lecture introductions. Unpublished Doctoral thesis, The University of Birmingham, Birmingham, England.

Young, L. (1990). Language as behaviour, language as code: A study of academic English. Amsterdam: John Benjamins.

Young, L. (1994). University lectures - Macro-structure and micro-features. In J. Flowerdew (Ed.), Academic listening: Research perspectives (pp. 159-176). Cambridge: Cambridge University Press.

\section{NOTE}

1 The British Academic Spoken English (BASE) corpus, devised by the University of Reading and Warwick. 